\title{
"CREAR NUEVAS VIDAS, CREAR NUEVOS BARRIOS" MEMORIAS Y TRANSMISIÓN GENERACIONAL SOBRE OCUPACIONES DE TIERRAS EN SAN FRANCISCO SOLANO (SUR DEL GRAN BUENOS AIRES).
}

\section{"CREATE NEW LIVES, CREATE NEW NEIGHBORHOODS" MEMORIES AND GENERATIONAL TRANSMISSION ABOUT LAND OCCUPATIONS IN SAN FRANCISCO SOLANO (SOUTH OF GREATER BUENOS AIRES).}

Santiago Nardin ${ }^{1}$

Resumen

En 1981 se produjeron ocupaciones masivas de tierras en el sur del Gran Buenos Aires que dieron lugar a la formación de seis asentamientos. Se trató de una modalidad de conformación de barrios populares por entonces novedosa, y a la luz de los acontecimientos posteriores, fueron juzgadas como acciones de carácter "fundacional", especialmente en lo que respecta a su matriz organizativa. En este artículo estudiamos las representaciones sociales que los protagonistas de aquella toma elaboran acerca de la acción directa y sus transformaciones. Intentaremos mostrar cómo un relato de características épicas, organizado a partir de una confrontación entre el actor colectivo que constituían los asentados contra la dictadura militar, convive con otro relato en el que ese "nosotros" es más un resultado que un punto de partida, producto de un ejercicio de demarcación de fronteras no siempre evidentes, ni mucho menos incuestionables. A su vez, las tomas posteriores son entendidas como el resultado de un conjunto de prácticas y conocimientos que integran el acervo familiar y que se transmiten generacionalmente; se comparte no sólo el saber hacer, sino también las dificultades y sus aspectos controversiales. Así, el orgullo asociado a su condición de fundadores, se combina con una disposición pedagógica para acompañar a sus hijos en las nuevas ocupaciones.

Palabras clave: Ocupaciones de tierras, memorias, representaciones sociales, identidad, alteridad

\section{Abstract}

In 1981 there were massive land occupations in the south of Greater Buenos Aires and as a result six

\footnotetext{
1 Instituto de Investigaciones Gino Germani (Facultad de Ciencias Sociales, Universidad de Buenos Aires) / CONICET.Argentina.URL: https://orcid.org/0000-0001-6374-7791Email: santiagonardin@gmail.com
} 
settlements emerged. It was a way of creating popular neighborhoods at the time novel, and retrospectively they were judged as "foundational" actions, especially with regard to their organizational aspect. In this article we study the social representations that the protagonists of that occupation about direct action. We will try to argue that in the representations of our interviewees two elements are combined: a representation of epic characteristics, structured on the basis of a confrontation between the collective actor that constituted the settlers against the military dictatorship, coexists with another representation in which that "us" it is more a result than a starting point, product of an exercise of demarcation of borders not always evident, much less unquestionable. In turn, the subsequent occupations are understood as the result of a set of practices and knowledge that integrate the family acquis and that are transmitted generationally; not only the know-how is shared, but also the difficulties and their controversial aspects. Thus, the pride associated with their status as founders is combined with a pedagogical disposition to accompany their children in new occupations.

Key words: Land occupations, memories, social representations, identity, otherness

"Crear nuevas vidas, crear nuevos barrios" memorias y transmisión generacional sobre ocupaciones de tierras en San Francisco Solano (sur del Gran Buenos Aires).

Introducción

En el año 1981, en las postrimerías de la última dictadura militar argentina (1976-19863), se produjeron una serie de ocupaciones masivas de tierras en la zona de San Francisco Solano, en el sur del conurbano bonaerense, que dieron lugar a la formación de seis asentamientos - La Paz, Santa Rosa, Santa Lucía, El Tala, San Martín y Monte de los Curas (luego rebautizado Barrio 2 de abril)-. Se trató de una modalidad de conformación de barrios populares por entonces novedosa, y a la luz de los acontecimientos posteriores fueron juzgadas como acciones de carácter "fundacional", especialmente en lo que respecta a su matriz organizativa, luego replicada en otras ocupaciones de mediados de los años ochenta (Nardin, 2018a; 2018b).

En este artículo estudiamos las rememoraciones de los protagonistas sobre aquellas ocupaciones, el modo en que juzgan las transformaciones socio-territoriales y las nuevas 
ocupaciones que tuvieron lugar sobre terrenos lindantes casi dos décadas después y dieron origen al barrio La Matera. Intentaremos mostrar cómo un relato de características épicas, organizado a partir de una confrontación entre el actor colectivo que constituían los asentados contra la dictadura militar, convive con otro relato en el que ese "nosotros" es más un resultado que un punto de partida, producto de un ejercicio de demarcación de fronteras no siempre evidentes, ni mucho menos incuestionables. A su vez, las tomas posteriores son entendidas como el resultado de un conjunto de prácticas y conocimientos que integran el acervo familiar y que se transmiten generacionalmente; se comparte no sólo el saber hacer, sino también las dificultades y sus aspectos controversiales. Así, el orgullo asociado a su condición de fundadores, se combina con una disposición pedagógica para acompañar a sus hijos en las nuevas ocupaciones.

\section{Enfoque metodológico. Coordenadas para el estudio de memorias y representaciones sociales}

La materia fundamental de nuestra exploración son las entrevistas en profundidad, realizadas en el marco de un trabajo de investigación, docencia y extensión en San Francisco Solano², entre 2015 y 2018. Los relatos describen trayectorias personales, familiares y vecinales, comunican valoraciones sobre acciones propias y de otros, así como también los criterios en virtud de los cuales elaboran dichos juicios. El mundo simbólico y los procesos de significación social son el marco general en el que se inscribe nuestra indagación, especialmente la relación entre memoria y representación social (Bertotti, 2016). Toda representación social constituye una forma de conocimiento, refiere a la manera en que los sujetos sociales aprehenden y reelaboran las informaciones del entorno próximo o cercano sobre la base de la experiencia, pero también de las informaciones que recibimos y transmitimos a través de diversos medios e instituciones. Son, por lo tanto, un conocimiento socialmente elaborado y compartido (Jodelet, 1984).

Analíticamente, toda representación contiene elementos de información y valoración y se constituye a partir de dos procesos: objetivación y anclaje. El primero indica el modo en que se estructura y esquematiza una representación a partir de la "selección" de determinada información, y el segundo refiere a los procesos de incorporación de los nuevos elementos y su integración a los

\footnotetext{
2 Es una localidad ubicada en el sur del conurbano bonaerense, repartida entre los Municipios de Quilmes y Almirante Brown, y cuenta con rango de ciudad desde 1981
} 
marcos de sentidos preexistentes. En este proceso se constituye el "núcleo figurativo" que condensa los aspectos más sólidos y estables de la representación.

Toda memoria, por su parte, es una forma de representación social acerca del mundo que elaboran los individuos pero que se haya enmarcada socialmente; los recuerdos personales están inmersos en narrativas colectivas que sedimentan en conmemoraciones y rituales que favorecen su fijación. La memoria incorpora las vivencias de otros que le son transmitidas, de manera que el pasado puede condensarse o expandirse según el modo en que las experiencias pasadas son asimiladas (Jelin, 2002). La temporalidad de la memoria no se agota en los sentidos que se construyen acerca de determinados procesos del pasado, ya que se realiza siempre desde un presente y de acuerdo a un futuro deseado. El presente contiene y resignifica la experiencia pasada y se moldea por las expectativas, es decir, por la referencia a una temporalidad futura. Nuevos acontecimientos y coyunturas pueden introducir modificaciones en los marcos interpretativos para la comprensión de las experiencias pasadas.

Finalmente, y siguiendo a Elizabeth Jelin, memoria e identidad guardan una relación de mutua constitución. El núcleo de cualquier identidad está asociado a un sentido de permanencia a lo largo del tiempo y el espacio, de forma tal que rememorar algo de lo propio oficia como un sostén de la identidad. Una identidad colectiva se asienta sobre determinados hitos, se resaltan algunos rasgos de identificación grupal que refuerzan los aspectos constitutivos y enfatizan la diferenciación con los "otros" que definen los contornos de la identidad. En relación a este punto, hay que señalar que los hechos, lugares o personificaciones que son "seleccionados" pueden estar ligados a experiencias vividas por las personas o bien pueden ser transmitidos por otros; pueden remitir a acontecimientos concretos o más bien idealizaciones o proyecciones. Para que sean "memorables", estos acontecimientos deben romper con cierta memoria habitual. En la vida cotidiana, los comportamientos rutinarios son mayoritariamente no reflexivos, aprendidos y repetidos. Cuando se rompe esa rutina, los sujetos se involucran de una manera diferente ya que se movilizan sentimientos que jalonan la búsqueda de un sentido y activan un compromiso afectivo que vuelve a estos momentos "memorables". El acontecimiento, de esta forma, se expresa de un modo narrativo y se vuelve comunicable, ya que se trata de un hecho que rompe con el flujo rutinario, de lo esperado. La irrupción desafía al sujeto a reflexionar e intentar eslabonar el evento disruptivo con un mundo de significaciones conocidas. 
Memorias y representaciones sobre la toma de 1981. Mito de origen, alteridades y criterios en conflicto

La domesticación de un territorio hostil y cercado

El Tala debe su nombre al único árbol que había en la zona en la que, con hilos y palos, se trazaron las 21 manzanas del asentamiento en noviembre de $1981^{3}$. Bajo la sombra de aquel árbol se realizaron las primeras reuniones de la comisión de vecinos y, por ese motivo, posteriormente fue el espacio asignado para el emplazamiento de la iglesia. Antes de que llegaran los primeros ocupantes organizados por el párroco de la iglesia de Itatí, Raúl Berardo, y las Comunidades Eclesiales de Base $(C E B)^{4}$, el rectángulo ubicado entre las calles 813, 819, 895 y el arroyo San Francisco es descripto por los habitantes como un lugar hostil e inhabitable, un basural en el que las fábricas de la zona -la más importante era y sigue siendo Cattorini, que produce envases de vidrio- arrojaban sus desechos.

La identificación del territorio como un espacio inhabitable se articula con el énfasis que asume la intervención colectiva sobre el espacio que lo transforma materialmente y lo dota de significados muy particulares. Esta "domesticación del espacio" (Duhau y Giglia, 2008) subraya la dimensión sociocultural presente en la producción de todo orden socio-espacial más allá de las constricciones sociales y económicas, es decir que es un fenómeno irreductible a una "lógica de la necesidad" (Abramo, 2012).

Raúl llegó con el primer grupo de ocupantes al barrio, y desde hace 27 años que colabora con uno de los dos comedores comunitarios que hay en el Tala, en el que también trabajan su ex esposa, una de sus hijas y su hermano. El lugar donde se emplazó el asentamiento es presentado como un espacio amenazante por la presencia de animales salvajes frente a lo cual se destaca la tarea domesticadora de los recién llegados.

Raúl: no había ni zanja, era basural. Basural del barrio viejo, Había caballos muertos, perros muertos, arañas así [hace una seña con las manos], víboras...todavía tenemos allá en la iglesia, en formol, unas cuantas víboras.

\footnotetext{
${ }^{3}$ No nos vamos a detener en una reposición detallada de las tomas de 1981. Ver Cuenya, 1984; Izaguirre y Aristizábal, 1988; Fara, 1988; Merklen, 1991, 1997; Cravino, 1998, 2001; Vommaro, 2006, 2007; Cravino y Vommaro, 2018.

${ }^{4}$ Ver Woods, 2005, 2007; Wegener, 2008; Vommaro y Marchetti, 2008.
} 
Los asentamientos tuvieron que hacer frente a un cerco policial durante los primeros 6 meses sobre toda la zona de las ocupaciones que, a la altura de El Tala, cruzaba la calle 895. Este cerco, especialmente intenso en los primeros meses, impedía el ingreso de materiales y de suplementos básicos para el sostenimiento de las ocupaciones, los policías hostigaban y amedrentaban sistemáticamente a los ocupantes y esto derivaba en grescas ocasionales y detenciones. Los ocupantes aprovechaban la noche para vulnerar el cerco y pasar materiales de construcción para levantar las precarias viviendas, principalmente maderas y chapas. Transcurridos los primeros meses de hostigamiento más intenso, el cerco fue relajándose progresivamente hasta la guerra de Malvinas, momento en el que la dictadura militar abandonó esta estrategia de asedio sobre los asentados. El verano de 1982, sin embargo, fue muy duro para las seis tomas de Solano y Brown, y se cobró la vida de 14 chicos que murieron debido a enfermedades provocadas por la extrema dureza de las condiciones de vida en los asentamientos.

En el primer momento, las viviendas eran apenas unas chapas y maderas, sino directamente carpas en los lotes, y carecían de cualquier servicio ${ }^{5}$. La primera bomba de agua, donada por la Confederación General del Trabajo (CGT) de Quilmes en diciembre de 1981, fue un hito para la historia del barrio. Luego de la bomba de agua, la siguiente conquista fueron el servicio de luz y la organización de una heladera comunitaria para guardar los medicamentos de todo el barrio.

La amenaza inminente del desalojo, la imagen de las topadoras y la decisión de que las mujeres y los niños se pusieran delante de ellas es una referencia constante en todos los relatos de los entrevistados que participaron de la toma. Este acontecimiento es parte de un relato canónico de los ocupantes fundadores de El Tala, se transmite generacionalmente y se ha recreado en los festejos del barrio, en canciones y obras de teatro que se realizaron en el barrio.

\section{Consolidación y crisis de la matriz comunitarista eclesial}

El cerco policial condensa la acción de una autoridad no reconocida. En los relatos de los entrevistados se ubica la dictadura militar como una figura de alteridad ante la cual se legitima no sólo la resistencia sino la acción de la toma. Como contracara, la iglesia, y en particular el párroco

\footnotetext{
${ }^{5}$ Las redes de sentido que se elaboran en torno a la vivienda no forma parte de nuestro análisis. Para un análisis de las representaciones sociales acerca de la construcción de la vivienda en los barrios populares, ver Maneiro, 2017.
} 
Raúl Berardo, son representados como los actores que canalizan las demandas de tierra y organizan a los ocupantes para su resolución.

El grupo de ocupantes fundadores que entrevistamos acuerda en reconocer la centralidad de la iglesia en la planificación y ocupación de los terrenos, así como en la organización posterior del asentamiento. Las CEB se habían formado en la zona de Solano a partir de 1976 por iniciativa de Raúl Berardo y avalado por el Obispo de la diócesis de Quilmes, Jorge Novak, quien brindó un apoyo discreto pero significativo a las tomas. El trabajo de las CEB excedía largamente las actividades de evangelización ya que desarrollaban tareas comunitarias con jóvenes, abordaban problemáticas barriales y promovían la autorganización. Además de la iglesia, las ocupaciones contaron con el apoyo del Servicio de Paz y Justicia (SERPAJ), la CGT local y abogados del Partido de Lomas de Zamora que patrocinaron a los habitantes de los jóvenes asentamientos.

En el altar de la capilla ubicada en la esquina de 815bis y 894, una imagen de Raúl Berardo ocupa un lugar central. Si bien todas las formas de evocación suponen un ejercicio creativo que se realiza desde el presente, las memorias ligadas a procesos especialmente movilizantes para la biografía de los sujetos requieren un ejercicio reflexivo adicional que consiste en eslabonar el evento disruptivo con un mundo de significaciones conocidas de forma tal que esta memoria se vuelva mínimamente coherente, comunicable. En el caso de Cristina, nombrar al Padre Berardo asume la forma de una reparación por el tiempo que no pudo ser nombrado debido al temor a las represalias de la dictadura.

Cristina: La iglesia fue la primera organización que estuvo acá al pie, con los misioneros, trayéndonos la Virgen, haciendo los acampes con nosotros, acompañando a través del padre Raúl Berardo, que fue nuestro líder máximo. Y que lo teníamos que negar, porque si le dábamos el nombre de él lo mataban. Él tuvo que después escapar, tuvo que irse a Brasil, estábamos en dictadura. O sea, sabíamos que había un cura atrás pero tampoco lo podíamos nombrar. Hoy puedo decirlo, después de muchos años, decir Raúl Berardo, con todo el orgullo de decir un cura que estuvo acompañándonos, eso vino después. Antes era miedo.

Cristina se asume como parte de los entramados comunitarios promovidos por la iglesia para la planificación de la ocupación y organización del asentamiento. Su inscripción en un colectivo se enlaza con una representación que enfatiza el carácter autónomo del proceso cuando afirma que "nadie nos organizó, acá nos organizamos nosotros con la ayuda de la iglesia".

Junto con la iglesia, el otro actor relevante de los asentamientos fueron los delegados de manzana, quienes estaban en la base de la estructura organizativa. Las asambleas de manzana 
elegían al delegado manzanero y los delegados, a su vez, definían una comisión coordinadora de los barrios. Por otro lado, un plenario del barrio definía una comisión interna que acompañaba y coordinaba con los delegados manzaneros las gestiones con funcionarios públicos y las obras de mejoramiento del asentamiento. El delegado, -más allá de las referencias al modelo fabril que identifican Izaguirre y Aristizábal (1988) -, es la personificación de la matriz comunitarista de la organización del asentamiento que impulsaban las CEB. En los relatos de los fundadores, la figura del delegado está asociada a la etapa inicial de la ocupación, al momento de mayor confrontación con las fuerzas de seguridad, a la organización de los esfuerzos colectivos para la realización de mejoras, y al espacio de encuentro en asambleas periódicas (en ocasiones una por día) para la socialización de la información y la discusión colectiva de las medidas a tomar. A su vez, en los relatos de este grupo de entrevistados, la legitimidad del delegado está fundada también en su separación de los políticos y la política.

Raúl: Este barrio, desde que nació, fue apolítico. Más allá de que cada cual tiene su cartel, pero en lo que se llama el barrio propiamente dicho, porque teníamos comisión interna y cada manzana tenía su delegado, yo soy delegado de mi manzana. Toda la vida fui delegado de mi manzana.

El carácter "no político" de los delegados cobra un sentido particular a la luz de los cambios que sufrieron los modelos organizativos de las ocupaciones luego de la caída de la dictadura militar, especialmente durante los primeros dos años del gobierno de Alfonsín (1983-1989), momento en el que este grupo de vecinos identifica como el de la "Ilegada" de los políticos al barrio. Desde esta perspectiva, los políticos son definidos por intereses particularistas y se les atribuye la responsabilidad en la fragmentación del colectivo de vecinos. Las razones que llevan a la progresiva desarticulación del entramado organizativo es objeto de debate en las investigaciones académicas, pero todas acuerdan en señalar la configuración de un nuevo escenario político definido por: a) concesiones parciales del nuevo gobierno provincial de signo radical -principalmente la cesión de tierras por etapas- que generó fuertes desavenencias entre y dentro de los barrios que integraban la coordinación; b) la demanda de institucionalización y la formalización de instancias jerárquicas que trastocó ciertas modalidades asamblearias para la toma de decisiones; c) la reactivación de la militancia política luego de años de opresión política y, fundamentalmente, la denominada "renovación" dentro del peronismo que introdujo un nuevo dinamismo al activismo territorial; d) el alejamiento del Padre Berardo en 1983 y el debilitamiento de las CEB. 
La oposición entre delegados y políticos personifica y resume buena parte de estos procesos. En los relatos se combinan evocaciones nostálgicas de momentos pretéritos de fortaleza comunitaria con el rechazo de las acciones de ciertos delegados que se habrían apropiado de espacios y recursos que pertenecían al barrio, así como también la reprobación moral de "malos políticos".

Dos relatos de Cristina sintetizan algunos de los aspectos reseñados:

Cristina: Un político trajo un montón de familias una noche en un camión y nos enfrentamos, los vecinos no querían dejarlos entrar, porque este espacio, si en algún momento lo podíamos apropiar nosotros, queríamos que fuese la escuela, o la comisaría, o alguna cosa que nos sirviera para todo el barrio.

Cristina: El martillo de uno era el martillo de todos, y cuando terminaban de clavar acá iban a clavar a la casa del vecino. (...) Cuando venían los de la municipalidad, después de que empezaron a entrar los censos, nos prestábamos los hijos. Nos prestábamos los hijos para que no los tacharan y les hicieran el censo.

Pero la impugnación trasciende a los delegados sospechados y se proyecta sobre el conjunto de los vecinos de El Tala, quienes parecen desentenderse de los asuntos colectivos a medida que se conquistan algunas mejoras en la infraestructura, los servicios y las viviendas. Esta preocupación ya estaba presente a los pocos años de realizada la toma y quedó registrada en una canción que fue parte de la obra de teatro que se montó para el festejo de los 10 años del barrio, en 1991.

\footnotetext{
No se acaban los peligros, ni se acaban las amenazas. La lucha a veces se olvida al revocarse la casa.
}

Este fragmento ilustra las preocupaciones de los activistas barriales por la creciente apatía y desafección de sus vecinos y propone, al mismo tiempo, una explicación que remite a la lógica contradictoria de ciertas reivindicaciones que jalonan la organización colectiva. Svampa y Martuccelli (1997), observaron que ciertas reivindicaciones políticas -entre las que podríamos incluir las demandas de hábitat- deben ser comprendidas, antes que como el paso de lo "privado" a lo "público", como una "politización de lo privado", como una forma de establecer, por medio de la acción colectiva, una separación real entre ambos dominios: "A lo que aspira es a sustraer la vida 
cotidiana de lo político, a trazar una frontera que permita vivir una vida personal" (Svampa y Martuccelli, 1997: 401). Mirado desde esta perspectiva, el eclipsamiento de la acción colectiva podría ser interpretado como una consecuencia del logro -aunque sea parcial- de los objetivos propuestos inicialmente. La acción directa en el campo del hábitat y la vivienda, en tanto busca sustraer y constituir un ámbito privado por medio de una acción colectiva, articula en su interior confrontación e integración.

Más allá de la declinación de la experiencia organizativa de El Tala, - - , mejor dicho, precisamente por eso- la memoria nostálgica sobre aquel momento fundacional constituye un organizador de las representaciones de los habitantes que participaron activamente de la toma. La pertenencia al grupo de los fundadores opera como un refugio especialmente entre quienes tienen menor participación en las instituciones colectivas que estos vecinos crearon y siguen llevando adelante (la capilla, el comedor, el centro de primera infancia). Tal es el caso de Raúl, que participa del comedor como cocinero, en una relación que pivotea entre el compromiso militante y la relación laboral.

Raúl: Y ahora de los fundadores quedamos poquitos, murieron como seis, siete. Muy pocos quedaron...(inaudible) la vieja de la panadería, 5 o 6, éramos 21, un delegado por manzana. (...) Empezaron a meterse los políticos adentro, y desarmaron toda... no es tanto lo que se desarmó porque todavía sigue más o menos, los viejos nos seguimos hablando.

Sin embargo, la experiencia de la ocupación y de los primeros años de organización del asentamiento no se agota en una referencia meramente nostálgica ni tampoco permanece estanca. Ella se actualiza y recrea, en función de los acontecimientos posteriores que proveen claves de lectura sobre fenómenos presentes, guías que permiten a los sujetos autoadscribirse roles. Las operaciones reflexivas involucradas en este proceso son un aspecto central de nuestra indagación sobre las representaciones que este grupo de habitantes fundadores elaboran sobre la toma de La Matera y el derrotero de El Tala.

Las imágenes de la alteridad

Un relevamiento de noticias publicadas en esos años nos permite ilustrar el tratamiento mediático que recibieron los protagonistas de las tomas de San Francisco Solano. Las referencias a los "villeros", "usurpadores", las "villas" son muy recurrentes. "6.000 villeros invaden terrenos en Solano"; "1.500 familias forman una nueva villa en sólo 3 días", son los titulares de las notas en el periódico local El 
Sol en su edición del $1^{\circ}$ de diciembre de 1981. En los medios también hay entrevistas al cura Raúl Berardo y miembros del obispado de Quilmes quienes niegan un involucramiento directo con la organización de las tomas -afirman la existencia de una comisión de vecinos- pero reconocen que acompañan a los ocupantes como parte de sus "tareas pastorales" y manifiestan su preocupación por la situación de los asentados.

En un recuadro del periódico se cita una comunicación de la Sociedad de Fomento del Barrio La Paz en la que sus integrantes niegan cualquier participación en las tomas, en respuesta a lo que había informado "un medio capitalino":

Ante esto, los fomentistas, muy molestos por cierto, señalan "que la sociedad de fomento nada tiene que ver en la ocupación tierras fiscales". También manifiestan "lo doloroso y dramático de que supuestas comisiones establecidas en el lugar de las tierras a ocupar cobrarían sumas de dinero, comerciando con la necesidad de gente sin recursos, hacen necesaria esta aclaración pues las entidades de bien público, cumpliendo funciones altruistas, no deberían verse nunca envueltas en hechos de esta naturaleza a raíz de versiones de fuentes de muy poca confianza y veracidad".

(Diario El Sol, 22 de diciembre de 1981)

La sociedad de fomento era la institución asociativa que nucleaba a los vecinos de los barrios conformados a partir de la compra en loteos populares y tenían como principal tarea la coordinación de esfuerzos colectivos y la gestión ante organismos públicos para la provisión de los servicios de los que carecían. Era, por tanto, la institución que encarnaba los imaginarios de progreso, ascetismo y dedicación propios de los "pobres respetables" (Merklen, 1997). El descargo de la sociedad de fomento denuncia a los usurpadores -no sólo de tierras sino también de nombres-y siembra una sospecha sobre ventas de lotes en las ocupaciones por parte de los organizadores que se "aprovecharían" de la situación de desventaja de personas sin recursos.

En los relatos de los entrevistados, las referencias a la villa y los villeros tienen una gravitación muy importante; registran esa imputación desacreditadora y apelan a una estrategia de delimitación y desplazamiento.

Raúl: En principio, todo el mundo se creía que iba a ser una villa, una casa al lado de la otra. Teníamos una comisión interna, se delimitaron los terrenos, las manzanas, las calles, nadie quería villa. 
Como observó Oscar Fara (1988), el modelo de urbanización de los asentamientos procuraba seguir el trazado de manzanas como forma de continuar el modelo del loteo popular predominante en el ciclo pasado, pero también bajo la creencia de que eso disminuía las posibilidades de desalojo. A su vez, el rechazo a la "villa" remitía no sólo a un modelo de urbanización sino también suponía la figura del "villero", la contraparte del "buen pobre", identificado como un sujeto carente de atributos morales, poco propenso al trabajo, sino directamente un desvalido (Merklen, 1997).

Sin embargo, en los relatos también hay una segunda personificación, el especulador o dominguero, es decir, aquel que procuraba obtener algún lucro o beneficio y que no lo destinara para vivienda familiar. Frente a situaciones que transgredían los criterios establecidos, los delegados debían agudizar su "ojo clínico" -en los términos de Cristina- con el objetivo de descifrar las motivaciones de quienes ocupaban un lote, o esperaban hacerlo. Incluso Cristina llegó al barrio cuando los terrenos ya habían sido distribuidos y recién pudo instalarse cuando uno de los lotes no estaba siendo ocupado de manera estable.

Lo interesante de esta reflexión es que nos permite ingresar al modelo de ocupante ejemplar imaginado por quienes protagonizaron la toma de 1981.

Cristina: Los pobres tenemos ojo clínico, decíamos siempre nosotros, y sabíamos aquel que quería un terreno para negociarlo después y aquel que realmente lo necesitaba porque pensaba en su futuro y quería formar una familia y necesitaba un terreno, y era consciente de que no se lo iba a poder comprar.

Aquí es muy claro cómo el modelo de ocupación se realizó siguiendo un patrón familiar clásico (una pareja joven heterosexual con hijos), que se asociaba con la noción de progreso. La dimensión sacrificial involucrada en la producción del espacio y el deseo de radicar familias organizadas trabajadoras confirieron legitimidad a la acción directa y a la transgresión de la propia privada.

\section{Criterios en conflicto}

Ahora bien, los ocupantes y organizadores del asentamiento debieron lidiar con situaciones particulares que difícilmente podían resolverse aplicando criterios tan necesarios como rígidos y generales. El futuro barrio debía integrarse por familias trabajadoras -aquellas que personificaban el progreso- que no tuvieran otra residencia y que permanecieran de forma estable durante la 
ocupación. Los casos que se ubicaban por fuera de estos parámetros podían ser objeto de cuestionamientos, sospechados de ser domingueros o de carecer de atributos morales, portadores de vicios o carentes del ascetismo que exigía la integración al espacio común que era el asentamiento. Esta situación conflictiva persiste en las memorias de los delegados y organizadores -que debían revisar y flexibilizar los propios criterios- como también de los ocupantes que fueron objeto de algunas de estas acusaciones y tuvieron que lidiar con la suspicacia y el recelo del entorno.

Cristina: La prioridad era tener hijos y que vivas. Acá en la manzana tuvimos un muchacho solo y lo defendimos ante muchísima gente porque no tenía hijos, pero era un muchacho que venía del trabajo y se ponía a limpiar su terreno, porque tenía que hacer el mismo trabajo que hacía yo acá.

Raúl: Inclusive los que se pararon sobre las supuestas calles que habíamos demarcado los habíamos sacado. Y a los "domingueros" también los habíamos sacado. Los domingueros eran esos que habían agarrado un terreno y venían recién un fin de semana y si pasaba algo se quedaban. Los sacábamos y poníamos a otra persona. (...) Teníamos una inteligencia para saber quién tenía un terreno, quién estaba especulando, quién no se quería arremangar las tobilleras, quién mandó al pariente para ver si tenía suerte o no y después revendía.

Lidia había llegado en marzo de 1982 cuando el alquiler en la Ciudad de Buenos Aires se le volvió insostenible. Una parienta lejana que vivía cerca de El Tala le había mencionado que los alquileres eran más accesibles y cuando llegó se enteró que "estaban dando terrenos". Ocupó uno con sus dos hermanas, pero ellas no pudieron permanecer en el asentamiento porque tenían hijos de unos pocos meses. Pero Lidia trabajaba como empleada doméstica con cama adentro y solo podía estar en su lote los fines de semana, incluso cada quince días.

Lidia: Los que veníamos los fines de semana los sacaban, y yo era una "fin de semana" porque yo trabajaba toda la semana y también teníamos...con los vecinos que nos querían sacar.

Otro problema relativo a la organización de la ocupación tenía que ver ya no con los "quiénes" sino con los "dónde". La ocupación de El Tala se vio desbordada por la constante afluencia de familias que, anoticiadas de las tomas, se acercaron a los distintos asentamientos de la zona con la esperanza de encontrar un lote, y así se fueron asentando en zonas que originalmente habían sido destinadas para otras funciones: espacios verdes, instituciones públicas y una franja liberada lindante al arroyo, respetando los parámetros fijados por la normativa vigente de forma tal que luego se facilitara la tan ansiedad legalidad. El planteo de estas controversias, las negociaciones y resoluciones alcanzadas 
por los vecinos nos hablan de los criterios puestos en juego por los ocupantes. A pesar de las presiones, resolvieron mantener el tamaño de los lotes, aproximadamente 10 por 30 metros, y hubo una especial preocupación por preservar el espacio asignado a la capilla.

Cristina: Igual que el terreno de la capilla, no sabés... A mí me tocó estar al lado, levantarme y defenderlo a la hora que sea, sabés las veces que se nos vinieron a meter familias. $Y$ con el dolor de decirles no, aunque vinieran con tres pibes, esta capilla es la iglesia y la iglesia la vamos a defender porque necesitamos una iglesia. En este barrio nos quedamos... no sé si ya les habrán dicho, no tenemos espacios verdes, porque la premisa era la familia, pero sí defendimos el terreno de la capilla. Yo lo defendía, es mi segunda casa. Es mi segunda casa, ¿no? Y la defendimos. No solamente yo, sino que... A mí me tocaba dar el grito siempre, y llamar a los vecinos para que, bueno, decime dónde estás y te vamos a conseguir otro terreno, pero este no. Este lo defendimos a capa y espada el terreno de la capilla.

Estas situaciones continuaron durante varios años. El fin de la dictadura supuso una reformulación de las dinámicas políticas bajo las cuales se desarrollaba el proceso organizativo del asentamiento. La aparición de los "políticos" en los relatos de los fundadores está asociado a una desorganización de las lógicas internas. Virginia es la fundadora del comedor más importante de El Tala, María de Nazareth, y desde que llegó al barrio en 1987 mantuvo un activo compromiso con el desarrollo del barrio.

Virginia: Nosotros primeros fuimos a tomar al costado del Viejo Bueno. Y de ahí nos sacan porque no se podía tomar, entonces, un diputado radical porque estaban en plena campaña, todo- conoce este predio y nos trae para acá. Nos trae a nueve familias. Y cuando llegamos acá, la gente que ya luchó, y que tenía sus casitas y estaban asentados, también nos quisieron echar. Porque esto era para una escuela... Y la mitad de la gente peleaba para que no, porque también éramos gente que venía en la misma forma que vinieron ellos, pero otros nos querían sacar. Bueno, y ganó la gente más buena [Se ríe]. Ganó la gente más buena... Y nos quedamos... Sí, nos quisieron prender fuego, nos quisieron que... Ellos cuidaban el espacio verde.

Cristina evoca este momento con mucha pesadumbre porque condensa una serie de contradicciones en un episodio muy intenso. Se identifica con el grupo de recién llegados en el "derecho a tener un techo", atribuye la responsabilidad de la situación a "un político que trajo un montón de familias una noche" y que eso derivó en un enfrentamiento entre los propios ocupantes ya asentados. 
Cristina: Y te imaginás que nosotros, ese día, no sé, un enfrentamiento de vecinos, algo terrible. Pelea, no les dejábamos que bajaran sus cosas. Lo mismo que habían hecho los militares con nosotros. Fue algo tan triste... yo me acuerdo que lloré mares esa noche. No podía ver que mis vecinos le digan, "fuera, váyanse", si nosotros unos años antes habíamos venido nosotros y habíamos usurpado. Y con el mismo afán de tener un techo para tu hijo, ¿viste? Y con qué derecho podíamos echarlos a ellos que también tenían hijos, ¿viste? Ay, no, fue tristísimo.

Los relatos precedentes nos permiten ilustrar los conflictos inherentes al proceso de conformación de un lugar común -el barrio-que en su interior contiene, al menos en su proyección, espacios públicos - plaza, escuela, capilla- y privados -la vivienda-, proceso que supone, a su vez, la definición de criterios de pertenencia y mecanismos colectivos que garanticen su cumplimiento pero que también arbitren frente a conflictos derivados de las dificultades de la aplicación de ciertos principios generales en situación concretas. Así, la memoria épica de los fundadores de El Tala construida a partir de la naturaleza hostil del espacio ocupado, de la confrontación con la dictadura militar y la legitimidad de la matriz organizativa comunitarista-eclesial se articula con un relato que enfatiza las tensiones internas y los dilemas propios de la constitución de un nosotros de fronteras porosas pero existentes.

\section{Los fundadores frente a las nuevas ocupaciones}

Más allá de la "necesidad". Los fundamentos legítimos de la transgresión.

Como vimos en la voz de quienes fueron sus protagonistas, el relato épico sobre la toma de 1981 constituye el mito de origen del barrio y de su comunidad, pero se inscribe en una representación que incorpora los conflictos internos que dan cuenta del trabajoso camino de la conformación de un "nosotros". A su vez, ofrece un punto de referencia para volver inteligibles procesos posteriores y una inscripción colectiva legítima desde la cual evaluar las acciones de los otros; las memorias deben ser tratadas, por lo tanto, como algo más que una evocación melancólica o nostálgica, constituyen representaciones dinámicas que se actualizan en los juicios y valoraciones de nuestros entrevistados.

Esta proposición se puede verificar en la asunción de un rol específico por parte de los ocupantes cuando se les interroga por las tomas posteriores ocurridas en la zona. Lo que predomina es una posición que combina un orgullo fundado en su condición de precursores y una predisposición pedagógica para acompañar a sus hijos en la organización de las nuevas tomas. 
Cristina: Nosotros somos hijos del barrio Dreymar y La Matera prácticamente son hijos del Tala. Porque son nuestros hijos que ya se hicieron adolescentes, formaron su familia, y ya acá no tenían lugar, ni siquiera una canchita para... y como fue programado, allá tienen espacios verdes, tienen jardines, tienen la escuela. Nosotros ni escuela, ni lugar para escuela.

Oscar: Porque esto fue, las tomas, esto fue el ejemplo. Fue el primer grupo de las tomas de bien, ordenadamente, y a partir de ahí... porque antes no existían las tomas.

Imposibilitados de acceder por las vías formales, la transmisión generacional de la acción directa como forma legítima de acceso a la tierra se asienta en esta experiencia compartida entre padres e hijos. Los fundadores saben que las ocupaciones nunca son acciones desesperadas o espasmódicas (Thompson, 1995) sino que demandan redes y recursos - materiales y simbólicos- para que puedan realizarse $y$, principalmente, sostenerse. Se requieren contactos e información, conexiones familiares o vecinales que puedan proveer de alimentos y bienes de primera necesidad el tiempo que dure la permanencia intensiva -frente al temor al desalojo o de que el lote sea ocupado por otro-, o para el cuidado de los hijos o de adultos mayores. Hay que movilizar articulaciones colectivas para llevar adelante gestiones ante organismos públicos, organizar reclamos, difundir la situación en los medios, convocar organizaciones e interpelar a los vecinos para forjar solidaridades más allá de los ocupantes. Estos son algunos de los aspectos que están involucrados en la acción de ocupación de un terreno y que ponen de relieve los recursos organizativos que requiere.

El esfuerzo que demanda la acción de ocupación se vuelve un elemento nodal en la determinación de los criterios de merecimiento y, consecuentemente, opera como respuesta defensiva ante las imputaciones desacreditadoras que instalan sospechas acerca de motivaciones venales. Como ya hemos argumentado en el primer capítulo, en un mundo popular urbano atravesado por la corrosión del derecho -como efecto de la intervención estatal sobre la cuestión social desde mediados de los años noventa- cobran relevancia las controversias al interior de las fracciones marginalizadas respecto de quiénes y por qué merecen (o necesitan) así como quiénes y por qué transgreden ciertas normas.

El efecto de estas transformaciones en el plano de las sociabilidades territoriales se expresa en la difusión de estrategias de distinción entre semejantes y la dilución de las alteridades radicales, vectores de nuevas formas de atomización a las que deben hacer frente las tentativas de organización colectiva. 
Enfatizar lo arduo y laborioso de la ocupación de tierras puede ser una forma de eludir las sospechas que pesan sobre sus protagonistas al definirla como una acción indiscutiblemente antieconómica. Dicho de otro modo, el sacrificio que demanda la ocupación de una tierra opera como la evidencia de que el sujeto que la protagoniza es merecedor en virtud de su necesidad.

Oscar: Entonces uno agarra, toma decisiones y se mete, por la necesidad de la gente, porque si no tuviera necesidad, no iría uno, no se arriesgaría a meterse en un lugar. Pero la necesidad, lo lleva a meterse a tomar esas decisiones. Entrevistador: Y para usted, si una persona tiene necesidad, le parece bien que vaya y participe de una toma, o...

Oscar: (...) Si estás vos en tu casa, que tengas un pequeño ranchito ahí, en ese lugar, yo no puedo ir a meter. Ya es ir a usurparte, a robarte. Ahora, si el municipio dice que ahí no se paga más impuestos hace treinta años y es una pérdida para el municipio, es un mugrerío para la zona, contaminación total, que queman mil cosas. Yo creo que si la gente tiene necesidad, y puede hacer su casa bien, ordenadamente...

En esta vía de acceso no desaparece la legitimidad del intercambio mercantil, expresado en la voluntad de pago por parte de los ocupantes. En el fragmento citado, esa valoración se expresa como su contracara, es decir, la legitimidad de la toma se asienta, en parte, en la morosidad de los propietarios y el estado de abandono del predio.

Como vimos, la transmisión generacional de la ocupación de tierras como forma legítima de acceso se combina con una representación normativa sobre el barrio y la vivienda familiar. En los relatos de los entrevistados se identifica una preocupación ante la creciente densificación, el desarrollo de la construcción en altura y la subdivisión de los lotes en los que los hijos y sus familias comparten terrenos, incluso el techo, con otros familiares.

Cristina: Mi vecina de enfrente ya se fue para arriba. Y mi comadre tiene tres hijos viviendo... Uno arriba, otro al costado y otro al fondo, y el terreno no se ensancha. Entonces, hay que hacer... Y dentro de unos años, no sé dónde irán a tomar, porque se viene la otra generación, que, ¿̇a dónde van a estar? Y los viejos, que ya tenemos la idea adentro, ¿̇abés cómo enseguida se la pasás? Ya hay un camino hecho. Nosotros, lógicamente, lo inventamos, pero ahora ya está el camino hecho. Sabés que la tierra acá en nuestro país sobra. Tomá el colectivo una hora y tenés campo, campo y campo.

La cuestión de la "necesidad" se dota de significaciones específicas; es "necesidad" de recrear un patrón familiar, un modelo de sociabilidad vecinal que requiere una cierta forma espacial para realizarse. Para concretarla, se apela al recurso de la acción directa cuya legitimidad se asienta en 
diversos elementos: una memoria colectiva barrial y familiar; en la inversión de la transgresión -la deuda de los propietarios de los terrenos con el municipio o una política pública fallida- y en la voluntad de pago como forma de restituir la integridad cuestionada; en el carácter inhabitable del espacio -descripto como un basural-y el trabajo invertido en su mejoramiento.

\section{Ocupación y controversias en La Matera}

A diferencia del espacio donde se emplazó El Tala, La Matera sí había sido objeto de intervenciones públicas; no era un "desierto" o un lugar indómito, sino que era un espacio definido a partir de una intervención estatal proyectada pero no finalizada y rodeada de controversias y trascendidos. Estos rumores -como observaron Elías y Scotson (2016) - operan como mecanismos de control social ya que regulan los contactos entre grupos sociales con diferentes niveles de estatus.

La toma de La Matera tuvo lugar en un predio en los fondos de El Tala, cruzando el arroyo San Francisco, el 31 de marzo de 2000. Esa zona, baja e inundable, había sido adquirida por el Gobierno de la Provincia de Buenos Aires a mediados de los años noventa para llevar adelante un plan de viviendas que, en 2001, luego de un largo tiempo de parálisis de las obras, fue ocupado por los beneficiarios del programa, por vecinos de la zona y otros que llegaron a través de vinculaciones con redes partidarias ligadas al peronismo local. De la toma también participaron organizaciones de desocupados con fuerte anclaje en San Francisco Solano con relaciones con uno de los curas de la zona, lo que motivó un enfrentamiento con las autoridades eclesiales, algunas de las cuales se habían involucrado en las ocupaciones de 1981 pero que, en este caso, rechazaban la toma ${ }^{6}$.

Entrevistador: Y el proceso de La Matera, ¿fue parecido a este? Cristina: Fue muy parecido pero a la vez distinto, porque era un barrio que ya estaba delimitado (...) Cuando se lo cedieran a la familia, iba a mantener los pozos ciegos, los terrenos marcados, y algunos ya hasta con su vivienda construida, era un barrio programado. Bueno, la necesidad y el negocio de algunos, porque fue también un negocio, ¿no? Armó la gente por otro lado y lo tomaron antes de que se llegara a hacer esto (...) Porque a la gente que estaban anotadas, que había que anotarse en la municipalidad y todo esto, un trabajo previo organizado... Se les fue todo a la miércoles.

\footnotetext{
${ }^{6}$ Sobre la participación de la iglesia católica en conflictos territoriales y, en particular, de la diócesis de Quilmes, ver Woods, 2007; Wegener, 2008. Sobre la génesis del movimiento de desocupados de San Francisco Solano y su vinculación con la comunidad parroquial, ver Pinedo, 2010.
} 
La Matera es un barrio objeto de controversias entre los vecinos de El Tala; existen relatos muy diversos respecto de los ocupantes y sus motivaciones, así como representaciones heterogéneas en relación a las condiciones de vida de los habitantes. Dentro del grupo de los tomadores, sin embargo, predomina una mirada compartida, al menos en sus trazos generales, definida por una posición pedagógica y de acompañamiento frente a las nuevas ocupaciones. Cuando Cristina relata la ocupación de La Matera se sorprende por "cómo se repite la historia" y traza un paralelismo con su historia familiar.

Cristina: Mirá cómo se repite la historia. Cuando se toma este barrio, yo estoy internada en el hospital de Solano pariendo mi hija. Cuando se toma La Matera, mi hija vivía... Se había tomado el barrio Agustín Ramírez, que era... atrás del Agustín Ramírez, el San José... el 3 de Mayo y el San José en Varela, y mis hijas fueron allá, ya estaban casadas, tenían una hija y estaba otro en camino. Tomaron allá. Allá había toma, allá nos vamos. Y... mi hija está internada, mi yerno se entera que estaban tomando La Matera, agarró cuatro chapas, a las nenas se las llevó a la otra abuela y se vino a La Matera. Mi nieto está cumpliendo, el mismo día, el 31 de marzo, mi nieto cumple 16 años. Fijate la vida, cómo Dios hace las cosas. Y cuando una después lo relaciona te da hasta risa, decir... Bueno, estamos signados por eso, crear nueva vida y crear nuevos barrios.

La posición de referencia que asumen los fundadores cuando transmiten su saber hacer sobre las ocupaciones no desconoce las tensiones internas que ella supone, ni se limita a un relato monolítico, sin fisuras internas.

Raúl: Sí, todas las tomas son parecidas, con matices, pero son todas parecidas. Llegás, ponés cuatro palitos y viene el otro y te quiere correr, lo defendés hasta que vayas poniendo algo mejor y acá cuando vino la corrida esa que hicieron los militares creo en el 89, prendimos fuego toda la esquina. Decía a la noche que te iban a reventar el rancho...

Selectividad del vínculo y rechazo normativo. Los fundadores frente al Estado y los políticos.

Cristina construye un relato semejante al de Raúl cuando compara la toma de El Tala con la de La Matera y observa una diferencia sustancial que refiere al modo de actuación del Estado. Para estos entrevistados, la presencia del Estado suele estar asociada a una forma de intervención que, en cierta manera, desorganiza y fragmenta: a veces, desoye los reclamos; en otras ocasiones, los atiende parcialmente; y, en otras, posterga el cumplimiento de ciertas promesas. Ante este escenario, la 
forma de restituir niveles de certidumbre en el vínculo con el Estado se realiza a través de la personalización del vínculo.

Señalemos algunos hitos que hacen a la historia de la relación del grupo de fundadores con el Estado y los políticos en relación a las demandas de hábitat y vivienda. En un primer momento, durante el alfonsinismo, en el marco de las exigencias de formalización de los asentamientos, las asambleas debieron dotarse de una estructura interna que, de acuerdo a nuestros entrevistados, redundó en conflictos que quebraron ciertas solidaridades ${ }^{7}$. Luego, como parte de este mismo ciclo, las leyes de expropiaciones de los asentamientos establecieron entregas parciales de títulos -en virtud de la diversidad de situaciones ya que las tierras eran privadas y existían distintos "dueños"-, proceso que provocó nuevas diferenciaciones estatutarias entre el grupo de habitantes de las 21 manzanas: por un lado, los de adelante (hasta la calle 893) pasaron a tener título de propiedad, mientras que los de atrás (la última fila de manzanas que limita con el arroyo Piedras) no lo pudieron obtener hasta el día de hoy.

Cristina: Bueno, ahí con el tema de la escritura, que fue una gran lucha, ahí nos fraccionaron, ahí nos rompieron la primera... la primera ruptura de la estructura del barrio, nos rompen a través de la escritura, ¿por qué? Porque dieron por franja, ¿̇no? Entonces, pasamos a ser los de arriba y los de abajo. Fijate cómo, cuando quieren, nos hacen pelota. Entonces, pasamos a ser los que teníamos escritura y los que no. Y lamentablemente muchos de nuestra gente que más se movilizaba, que más... quedó en la franja de abajo. Y esto nos dividió.

Actualmente, la situación de la titulación permanece incierta y los avances solo se logran a través de las gestiones que realiza el Programa de Mejoramiento de Barrios (PROMEBA) ${ }^{8}$, un organismo estatal que promueve la participación comunitaria, aspecto especialmente destacado por los

\footnotetext{
${ }^{7}$ Este aspecto fue observado por Izaguirre y Aristizábal, 1988; Vommaro, 2007.

${ }^{8}$ EI PROMEBA surge en los años noventa con el objetivo de transformar el hábitat popular vía la provisión de infraestructura social básica, promover el acceso a la propiedad de la tierra y fortalecer la organización comunitaria. Se apoyaba en una concepción descentralizada-desconcentrada que trasladaba la responsabilidad de la ejecución a provincias y municipio. Inicialmente, su impacto en nuestro país fue esencialmente cualitativo, pero de bajo impacto cuantitativo. A partir del año 2002, en el marco de la crisis, se desarrolla una nueva fase experimental en el AMBA que se intensifica desde 2004. Este programa social y territorialmente focalizado de carácter remedial orientado a la reducción de la pobreza fue progresivamente integrándose de modo complementario a la política habitacional al especializarse en obras de infraestructura, conexiones domiciliarias y núcleos húmedos, regularización dominial y, solo en casos excepcionales, para construcción de viviendas (como, por ejemplo, relocalizaciones). Para un mayor desarrollo, ver Di Virgilio, 2012.
} 
entrevistados. Según relata Cristina, el acceso al título de propiedad es un trámite excesivamente oneroso.

Finalmente, hay una importante cantidad de referencias al rol del Estado en la construcción de una obra de infraestructura para evitar las inundaciones por el desborde del arroyo San Francisco en la división entre El Tala y La Matera.

Cristina: Al vecino que está viviendo desde hace treinta y pico de años y que sufre... Después, por obra de infraestructura mal pensada y sin consultar al barrio, acá nos construyeron un túnel que viene desde Almirante Brown, que las inundaciones que hoy sufrimos de la 93 para abajo, es agua de Almirante Brown. Hicieron un túnel aliviador de las aguas de allá y nos da acá. Cuando se construye, cuando se toma La Matera, hacen un terraplén. El agua viene de allá, topa con el terraplén, y se viene para nosotros. Y lo que no sale del arroyo, sale por las bocacalles de las esquinas. Esas fueron políticas entre el intendente, que cuando nos dimos cuenta estaba acá, y en ese momento festejamos, porque había una obra grande en el barrio, cuando después nos dimos cuenta de que...

En las discusiones acerca del terraplén, las razones que llevaron a su construcción, los beneficiados y perjudicados por dicha obra se activan valoraciones que exceden a la obra en sí y suponen juicios respecto de los vecinos de El Tala y de La Matera, las responsabilidades estatales y sus modalidades de intervención. Como pudimos ver en el relato de Cristina, ella subraya el carácter inconsulto de la obra y responsabiliza al intendente. Los relatos de otros tomadores son similares en cuanto a la ponderación de las responsabilidades de figuras técnicas y políticas, externas a los barrios involucrados, como "ingenieros" o "políticos".

Oscar: El barrio La Matera debe tener siete cuadras por siete, así, o diez por diez. Vino un señor, un ingeniero, hizo toda una pileta, todo terraplén. Ellos están debajo de la pileta. Entonces, ¿̇qué pasa? El agua, en vez de volcar al campo, antes volcaba al campo, ahora vuelca para allá.

El grupo de vecinos fundadores que presentamos en este análisis constituyen una parte importante de las tramas organizativas de El Tala pero no es la única. Uno de los aspectos que caracteriza a este grupo es la autonomía relativa que asumieron respecto de las redes estatal partidarias a lo largo de más de 35 años; una autonomía que no se traduce en una prescindencia sino en la construcción de vínculos selectivos con ciertas instituciones. Además del ya referido vínculo con la iglesia, los fundadores de El Tala tejieron relaciones con la Central de Trabajadores de 
la Argentina (CTA) de Solano que a mediados de los noventa desarrolló una importante actividad en la zona, y participaron de diversas iniciativas municipales y provinciales orientadas a la resolución de problemáticas ligadas a la regularización dominial, la provisión de infraestructura y la construcción de 47 viviendas y mejoramientos habitacionales. La diferencia con otras tramas organizativas es que los fundadores de El Tala no se integraron a la gestión directa de ciertos programas o iniciativas estatales sino que el vínculo se estableció por medio de contactos personales.

Un ejemplo de este tipo de interlocutoras es Elena González ${ }^{9}$, integrante del PROMEBA. Ella resume los atributos valorados por los fundadores que establecen cierta excepcionalidad entre los funcionarios estatales y los políticos. La primera cualidad de Elena es su participación en las ocupaciones de 1981, en el barrio La Paz - un barrio que desde su origen tuvo un involucramiento más intenso con partidos políticos y organismos estatales que EI Tala-; militó en las CEB y luego se integró a la Federación de Tierra y Vivienda. Posteriormente, continuó su militancia política y territorial en otra red de organizaciones de lucha por la tierra y la vivienda. Estas organizaciones promovieron los Consejos de asentamientos desde fines de los años ochenta, que integraron las seis tomas de 1981 y luego las de 1987 -Malvinas, La Paz 2, La Unión, 9 de agosto, Km. 13. Elena ingresó como empleada en la dirección de tierras municipales de Quilmes a mediados de los noventa, momento en que se crea la Casa de Tierras para la regularización dominial y se sanciona la ley de escrituración para los viejos loteos (la n²4374/94, conocida como la "Ley Pierri"). Desde allí, fue testigo también de las resoluciones que se tomaron para la creación de los asentamientos planificados, uno de los cuales fue el de La Matera. Luego, Elena se involucró en la gestión del programa Techo y Trabajo -con el que se construyeron las viviendas y los mejoramientos habitacionales-y más tarde del PROMEBA, como referente del área social.

Cristina: Elena González, ella tiene la historia. Y tiene una claridad en la cabeza. Pero todo lo que es ley y derechos de los vecinos, pero... la tiene. Y la pelea, desde hace muchos años que está. Hace muchos años que está ahí, gracias a Dios. Porque son esas personas que no negocian. Porque acá tuvimos mucha gente que peleó, mucha gente que... valor, pero bueno, a la larga terminaron negociando y se hicieron su rancho y chau, se quedaron o se fueron. O se enfermaron (se ríe).

\footnotetext{
${ }^{9}$ Su nombre fue modificado para preservar su anonimato.
} 
La ponderación que hace Cristina sobre Elena indica una escala de valores y criterios a partir de los cuales juzgan a "los políticos"; es una doble legitimidad la que combina conocimientos sobre normativas y leyes, cierta determinación e intransigencia ("luchar" / "no negociar") que se sostiene a pesar del paso del tiempo ("hace muchos años que está ahi”). El relato de Cristina, además, enfatiza una separación con la política, como un espacio diferenciado del barrio.

Sabina Frederic (2004) había observado que los "malos políticos" y los "buenos vecinos" conformaban imágenes que sintetizaban dos fenómenos articulados de la política territorial de los años noventa: profesionalización y moralización. Estos procesos ilustraban una separación de los "políticos" respecto de los "militantes sociales" y la constitución de una esfera específicamente política (identificada con la gestión y la tecnocracia), pero también indicaba el rechazo a la ausencia de una moralidad compartida asociada al naufragio de una "comunidad de referencia" para los políticos que, hasta ese momento, la constituían los villeros.

La exclusión de los militantes sociales de la carrera política en el caso descripto por Frederic implicaba su marginación y confinamiento en los territorios. Al contrario, el grupo de fundadores que siempre optó por mantener niveles de distanciamiento respecto de los políticos- emblematiza esta autonomía y el rechazo a los políticos en virtud de ciertas categorías morales y recrea -en los términos de Frederic- la comunidad de referencia anclada históricamente en un pasado de lucha y resistencia que se actualiza en las instituciones que llevan adelante. Es decir, a diferencia del caso descripto por Frederic, en el que los militantes sociales quedan marginados de la carrera política, en este caso no se construye un relato basado en la disputa sino que se recrea una comunidad desde la cual se juzga a los políticos y con los que se establecen vínculos selectivos.

Lógicamente, existen matices y diferencias entre el grupo de fundadores respecto del vínculo con los políticos. Elvira, por ejemplo, quien también fue parte de grupo de fundadores construyó un vínculo con uno de los referentes de una de las fracciones del peronismo de la zona y su valoración acerca de la política no se estructura en los términos comunitarios con que se expresa Cristina, por ejemplo. A partir de esa relación instaló un comedor comunitario y fue parte del entramado territorial vinculado con la distribución de diversos planes sociales. Lo relevante de su relato es que prescinde de la oposición barrio-política y se organiza en torno a las diferencias políticas existentes dentro de las distintas fracciones del peronismo. Elvira reconoce una distancia entre los políticos y quienes habitan el barrio, pero subraya la existencia de vínculos fluidos y sostenidos a lo largo de 
más de una década, que comenzó en los primeros años de los ochenta durante una inundación que golpeó duramente la zona.

Elvira: (...) Y este chico Pipo ${ }^{10}$, que vive... te digo dónde vive, que siempre vivió ahí. Él venía y nos llevaba a toda la gente allá a la sociedad de fomento. Yo igual tenía a mis hermanos, todo, viste, pero yo me iba allá.

Entrevistador: ¿Y el señor Pipo también participó de toda esta organización? Elvira: No, él iba y venía. Porque él nunca estuvo acá. Sí, venía de vez en cuando, cuando pasaban cosas él viene... A mí me conoce hace muchos años. Yo trabajaba en política con él. Pero no era que él estaba empapado acá en el barrio, no. Él tiene una hija que es concejal, creo. No sé si fue el año pasado o el otro año, que esta chica había que votarla a ella y bueno, él venía a hacer fama por acá. Pero en realidad ni la chica, esa vuelta y nunca más vino. Viste, que pasaba así...

A partir de estas relaciones, Elvira se involucró en el activismo territorial, organizó comedores con recursos que obtenía por las redes estatal-partidarias, participó de la distribución de planes de empleo y de mercadería desde los años noventa y fiscalizó para elecciones internas y generales. A partir de las vinculaciones con una fracción del Partido Justicialista local, participó también de las reuniones para la regularización dominial de los habitantes de El Tala que aún no pudieron acceder a los títulos.

\section{Conclusiones}

En este artículo revisamos las representaciones y las memorias de los protagonistas de la toma que dio origen al barrio El Tala, en 1981. También exploramos los relatos acerca del derrotero del barrio y la relación de estos vecinos con las nuevas ocupaciones de terrenos ocurridas en la zona. Procuramos reconstruir los sentidos asociados a la acción directa y su (i)legitimidad, el lugar del Estado, los políticos, las mediaciones territoriales y las sociabilidades barriales.

Observamos que las ocupaciones de tierras no pueden considerarse acciones meramente reactivas frente a situaciones de extrema carencia material, ni tampoco pueden comprenderse por su exterioridad a las relaciones del mercado o de las políticas estatales. La legitimidad de la toma de El Tala se asentó en una memoria reciente del loteo popular como forma de producción del hábitat,

\footnotetext{
${ }^{10}$ Su nombre ha sido modificado para preservar su anonimato. Se trata de un comerciante y referente político del peronismo local, opositor a la gestión del intendente Francisco "Barba" Gutiérrez (2007-2015) y cercano al actual intendente de Quilmes, Martiniano Molina, perteneciente a la alianza Cambiemos.
} 
que los protagonistas de la ocupación pretendían recrear bajo las nuevas condiciones impuestas por la dictadura. El prestigio de la iglesia ofrecía una contención ante las recriminaciones de los vecinos de los "barrios viejos" de que allí se iban a "formar villas", pero sobre todo brindaba un sostén frente a las amenazas represivas de la dictadura militar. Los fundadores enfatizan el esfuerzo y los riesgos involucrados en una toma de tierras y, con ello, buscan conjurar las sospechas de venalidad: los arduos trabajos de "domesticación" del espacio y el enfrentamiento con el cerco policial son algunos de los hitos que dan cuenta del sacrificio involucrado y evidencia el carácter antieconómico de la ocupación. Las instancias organizativas que se dieron los asentados subrayan la dimensión colectiva de la experiencia y contribuyen a despejar, también, las suspicacias en torno al lucro privado.

Un relato de características épicas, organizado a partir de una confrontación entre el actor colectivo que constituían los asentados contra la dictadura militar, convive con otro relato en el que ese "nosotros" es más un resultado que un punto de partida, producto de un ejercicio de demarcación de fronteras no siempre evidentes, ni mucho menos incuestionables. El asentamiento se regía por una serie de pautas cuya observación quedaban a criterio del "ojo clínico" de los otros ocupantes. Los conflictos y las controversias tensionaron -al mismo tiempo que constituyeron- al barrio y la identidad del grupo de los fundadores. ¿Qué criterios se elaboraron para la asignación de lotes y permanencia en la ocupación? ¿Qué sucede cuando el "ojo clínico" del pobre sugiere una excepción a la aplicación de dichos criterios? ¿Cómo evocan la experiencia aquellos que fueron sospechados de domingueros o que ocuparon espacios que inicialmente estaban destinados para espacios verdes, o para una escuela? Nuestros entrevistados rememoraron estas disputas -que habían derivado en dramáticos enfrentamientos- para ilustrar los aspectos contradictorios de una identidad colectiva definida simultáneamente por fronteras nítidas cuando la alteridad la encarnan las fuerzas de seguridad o un modelo de urbanización que identifican con "la villa". Pero, también, por límites difusos cuando el "otro" refiere a personas que no se ajustaban al modelo familiar definido para los ocupantes, o cuando no se establecían en el lote de forma permanente.

Los entrevistados reconocen la existencia de intercambios mercantiles y maniobras especulativas, vedadas de acuerdo a los criterios informales de la ocupación. Esta clase de acontecimientos conflictivos podían derivar en la expulsión de los ocupantes o en el establecimiento de ciertas excepciones a los criterios fijados y hacen referencia, fundamentalmente, a tres aspectos: a) los atributos de las personas que se instalaban -el modelo ideal era una joven pareja heterosexual de "trabajadores" con hijos -; b) al lugar donde se emplazaba, respetando la ubicación de una sola 
familia por lote y dejando libre los espacios destinados para el equipamiento urbano proyectado; y c) el tipo de prácticas esperadas, esto es, la permanencia constante durante la ocupación y el empeño en el mejoramiento del lote asignado. De cada uno de estos criterios, los fundadores nos han relatado, al menos, la aplicación de una excepción: el caso del joven que vivía sin hijos en el terreno, pero que fue defendido por algunos delegados por sus demostraciones de laboriosidad y ascetismo; o el grupo de ocupantes que llegó en 1987 (de la "mano de un político radical") y que se instaló en el lugar reservado para una escuela, son algunos de los ejemplos.

El inocultable componente nostálgico que tiñe las representaciones de nuestros entrevistados evoca un pasado definido por la unidad barrial, la solidaridad que se expresaba en la colaboración recíproca - "el martillo de uno era el martillo de todos" -, y en el involucramiento colectivo con la resolución de las problemáticas. El eclipsamiento de este momento coincidió con desiguales avances materiales y estatutarios entre los habitantes del barrio; algunas casas fueron levantadas más rápidamente y los habitantes de las manzanas más cerca del límite con Alicia Esther pudieron acceder a los títulos de propiedad. Coincidió también, a juicio de los entrevistados, con "la entrada de los políticos" al barrio, fenómeno que alteró las formas de acción colectiva que se habían desarrollado hasta el momento. El barrio -y las organizaciones que lo encarnan- se concibe como un espacio "apolítico", en oposición a una representación de la política identificada como inherentemente exterior y guiada por intereses particularistas que amenazan la unidad de los vecinos.

Sobre esta base, los fundadores manifiestan un sentimiento de pertenencia y orgullo, una suerte de "emblematización" del barrio en función de la cual establecen un vínculo selectivo y personalizado con diversos entramados políticos con el propósito de sostener las instituciones comunitarias que llevan adelante hasta el día de hoy. Las tomas posteriores son entendidas como parte de un conjunto de prácticas y conocimientos que integran el acervo familiar y que se transmiten generacionalmente. Se comparte no solo el saber hacer, sino también las dificultades y sus aspectos controversiales. El orgullo por su condición de pioneros, por lo tanto, se combina con una disposición pedagógica para acompañar a sus hijos en las nuevas ocupaciones.

\section{Bibliografía}


Abramo, P. (2012). La ciudad com-fusa: mercado y producción de la estructura urbana en las grandes metrópolis latinoamericanas. EURE (Santiago), 38(114).

Bertotti, M. C. (2016). Las relaciones entre las memorias dominantes y las que construyen los vecinos de un Centro Clandestino de Detención. IX Jornadas de Sociología de la Universidad Nacional de La Plata, Ensenada.

Cravino, M.C (1998). Los asentamientos del Gran Buenos Aires: reivindicaciones y contradicciones. En: Neufeld, M.R., Grimberg, M., Tiscornia, S., Wallace, S. (comps.), Antropología social y política. Eudeba, Buenos Aires.

Cravino, M. C. (2001). La propiedad de la tierra como un proceso. Estudio comparativo de casos en ocupaciones de tierras en el Área Metropolitana de Buenos Aires. Land Tenure Issues in Latin America, SLAS.

Cravino, M. C. (Org.) (2008). Los mil barrios (in) formales. Apuntes para la construcción de un observatorio del hábitat popular del Área Metropolitana de Buenos Aires. UNGS, Provincia de Buenos Aires.

Cravino, M.C. y Vommaro, P. (2018). Asentamientos en el sur de la periferia de Buenos Aires: orígenes, entramados organizativos y políticas de hábitat. Población \& Sociedad, Vol. 25 (2).

Cuenya, B. (1984). Condiciones de hábitat y salud de los sectores populares. Un estudio piloto en el asentamiento San Martín, de Quilmes. CEUR, Buenos Aires.

Di Virigilio, M (2012). Participación social y organizaciones sociales en la implementación de políticas orientadas a la producción social del hábitat en el área metropolitana de Buenos Aires, Argentina. Revista SAAP vol.6 no.1

Duhau, E., y Giglia, A. (2008). Las reglas del desorden: habitar la metrópoli. Siglo XXI, México.

Elias, N., y Scotson, J. L. (2016). Establecidos y marginados. Fondo de Cultura Económica, España.

Fara, Luis (1988). Luchas reivindicativas en un contexto autoritario. Los asentamientos de San Francisco Solano. En Jelin, E. (Comp.) Los nuevos movimientos sociales. CEAL, Buenos Aires.

Frederic, S. (2004). Buenos vecinos, malos políticos. Buenos Aires, Prometeo editorial, Buenos Aires.

Izaguirre, I. y Aristizabal. Z. (1988). Las tomas de tierras en la zona sur del Gran Buenos Aires. CEAL, Buenos Aires.

Jelin, E. (2002). Los trabajos de la memoria. Siglo XXI editores, Madrid. 
Jodelet, D. (1984). La representación social. Fenómeno, concepto y teoría. En Moscovici, S. Pensamiento y vida social. Paidós, Barcelona.

Maneiro, M. (2017). Melancolía, quebranto, tensión y disfrute. Representaciones sociales respecto de las experiencias de construcción de la vivienda en los barrios populares periféricos. InMediaciones de la Comunicación, 12(1).

Merklen, D. (1991). Asentamientos en La Matanza: La terquedad de lo nuestro. Catálogos Editora, Buenos Aires.

Merklen, D. (1997). Organización comunitaria y práctica política. Nueva Sociedad, 149.

Merklen, D. (2013). Las dinámicas contemporáneas de la individuación. En R. Castel, Kessler, G., Merklen, D., y Murard, N. (2013) Individuación, precariedad, inseguridad ¿Desinstitucionalización del presente? Paidós, Buenos Aires.

Nardin, S. (2018a). Viejas y nuevas tomas de tierras. Controversias en torno a la acción directa en asentamientos informales de la periferia de Buenos Aires. O Social em Questão - Ano XXI - no 42.

Nardin, S. (2018b). 'Los fundadores'. La épica y su reverso en las memorias de las tomas de tierras en San Francisco Solano. XI Seminario Internacional Políticas de la memoria: Memorias subalternas, memorias rebeldes. Octubre, Buenos Aires, Argentina.

Pinedo, J. (2010). Entre la misa y el piquete: una organización de trabajadores desocupados. Intersticios. Revista sociológica de pensamiento crítico, 4(1).

Svampa, M. y Martuccelli, D. (1997). La plaza vacía. Las transformaciones del peronismo. Buenos Aires, Losada.

Thompson, E. P. (1995). Costumbres en común. Crítica, Barcelona.

Vommaro, P. (2006). Acerca de una experiencia de organización social: las tomas de tierras y los asentamientos de 1981 en Solano. Revista de Historia Bonaerense, 13(31).

Vommaro, P. (2007). Las organizaciones sociales de base territorial y comunitaria en Quilmes: el caso de las tomas de tierras y asentamientos de 1981. IV Jornadas de Jóvenes Investigadores Instituto de Investigaciones Gino Germani.

Vommaro, P. y Marchetti, P. (2008). Construyendo territorio: Aproximación a las experiencias de las tomas de tierras y los asentamientos de 1981 en Quilmes. V Jornadas de Sociología de la UNLP.

Wagener, M. (2008). Una experiencia político-religiosa en el sur del conurbano bonaerense: tomas de tierras, asentamientos informales y comunidades eclesiales de base en la localidad de San Francisco Solano. IX Congreso Argentino de Antropología Social. Facultad de Humanidades y Ciencias Sociales - Universidad Nacional de Misiones, Posadas. 
Woods, Marcela (2007). Modalidades y límites de la intervención de la Iglesia Católica en conflictos sociales territoriales. De la mediación a la confrontación en la diócesis de Quilmes. En Cravino, C. (Editora) Resistiendo en los barrios. Acción colectiva y movimientos sociales en el Área Metropolitana de Buenos Aires.

Trabalho enviado em 12 de março de 2019

Aceito em 02 de fevereiro de 2020 